\title{
Advances in Financial Risk Management andEconomic Policy Uncertainty: An Overview
}

\section{Instituto \\ Complutense \\ de Análisis \\ Económico}

\section{Shawkat Hammoudeh}

Lebow College of Business Drexel University

\author{
Michael McAleer \\ Department of Quantitative Finance \\ National Tsing Hua University \\ Taiwan \\ and \\ Econometric Institute \\ Erasmus School of Economics \\ Erasmus University Rotterdam \\ and \\ Tinbergen Institute \\ The Netherlands \\ and \\ Department of Quantitative Economics \\ Complutense University of Madrid
}

\begin{abstract}
Financial risk management is difficult at the best of times, but especially so in the presence of economic uncertainty and financial crises. The purpose of this special issue on "Advances in Financial Risk Management and Economic Policy Uncertainty" is to highlight some areas of research in which novel econometric, financial econometric and empirical finance methods have contributed significantly to the analysis of financial risk management when there is economic uncertainty, especiallythe power of print: uncertainty shocks, markets, and the economy, determinants of the banking spread in the Brazilian economy: the role of micro and macroeconomic factors, forecasting value-at-risk using block structure multivariate stochastic volatility models, the time-varying causality between spot and futures crude oil prices: a regime switching approach, a regimedependent assessment of the information transmission dynamics between oil prices, precious metal prices and exchange rates, a practical approach to constructing price-based funding liquidity factors, realized range volatility forecasting: dynamic features and predictive variables, modelling a latent daily tourism financial conditions index, bank ownership, financial segments and the measurement of systemic risk: an application of CoVaR, model-free volatility indexes in the financial literature: a review, robust hedging performance and volatility risk in option markets: application to Standard and Poor's 500 and Taiwan index options, price cointegration between sovereign CDS and currency option markets in the global financial crisis, whether zombie lending should always be prevented, preferences of risk-averse and risk-seeking investors for oil spot and futures before, during and after the global financial crisis, managing financial risk in Chinese stock markets: option pricing and modeling under a multivariate threshold autoregression, managing systemic risk in The Netherlands, mean-variance portfolio methods for energy policy risk management, on robust properties of the SIML estimation of volatility under micro-market noise and random sampling, asymmetric large-scale (I)GARCH with hetero-tails, the economic fundamentals and economic policy uncertainty of Mainland China and their impacts on Taiwan and Hong Kong, prediction and simulation using simple models characterized by nonstationarity and seasonality, and volatility forecast of stock indexes by model averaging using high frequency data.
\end{abstract}

J EL Classification C58, D81, E60, G32

\section{Working Paper no 1417 June, 2014}

UNIVERSIDAD

COMPLUTENSE

MADRID 


\title{
Advances in Financial Risk Management and Economic Policy Uncertainty: An Overview*
}

\author{
Shawkat Hammoudeh \\ Lebow College of Business \\ Drexel University \\ Michael McAleer \\ Department of Quantitative Finance \\ National Tsing Hua University \\ Taiwan \\ and \\ Econometric Institute \\ Erasmus School of Economics \\ Erasmus University Rotterdam \\ and \\ Tinbergen Institute \\ The Netherlands \\ and \\ Department of Quantitative Economics \\ Complutense University of Madrid
}

June 2014

* The authors wish to thank the referees for their timely and helpful comments and suggestions on the papers comprising the special issue. For financial support, the second author wishes to acknowledge the Australian Research Council and the National Science Council, Taiwan. 


\begin{abstract}
Financial risk management is difficult at the best of times, but especially so in the presence of economic uncertainty and financial crises. The purpose of this special issue on "Advances in Financial Risk Management and Economic Policy Uncertainty” is to highlight some areas of research in which novel econometric, financial econometric and empirical finance methods have contributed significantly to the analysis of financial risk management when there is economic uncertainty, especiallythe power of print: uncertainty shocks, markets, and the economy, determinants of the banking spread in the Brazilian economy: the role of micro and macroeconomic factors, forecasting value-at-risk using block structure multivariate stochastic volatility models, the time-varying causality between spot and futures crude oil prices: a regime switching approach, a regime-dependent assessment of the information transmission dynamics between oil prices, precious metal prices and exchange rates, a practical approach to constructing price-based funding liquidity factors, realized range volatility forecasting: dynamic features and predictive variables, modelling a latent daily tourism financial conditions index, bank ownership, financial segments and the measurement of systemic risk: an application of CoVaR, model-free volatility indexes in the financial literature: a review, robust hedging performance and volatility risk in option markets: application to Standard and Poor's 500 and Taiwan index options, price cointegration between sovereign CDS and currency option markets in the global financial crisis, whether zombie lending should always be prevented, preferences of risk-averse and risk-seeking investors for oil spot and futures before, during and after the global financial crisis, managing financial risk in Chinese stock markets: option pricing and modeling under a multivariate threshold autoregression, managing systemic risk in The Netherlands, mean-variance portfolio methods for energy policy risk management, on robust properties of the SIML estimation of volatility under micro-market noise and random sampling, asymmetric large-scale (I)GARCH with hetero-tails, the economic fundamentals and economic policy uncertainty of Mainland China and their impacts on Taiwan and Hong Kong, prediction and simulation using simple models characterized by nonstationarity and seasonality, and volatility forecast of stock indexes by model averaging using high frequency data.
\end{abstract}

Keywords: Financial risk management, Economic policy uncertainty, Financial econometrics, Empirical finance.

JEL: C58, D81, E60, G32. 


\section{Introduction}

New research and techniques in economics and finance have been used to deal with important issues that have emerged from the 2008-09 Global Financial Crisis that started in the USA, the sovereign debt crisis that emanated from Europe in 2010, and the resulting policy uncertainty in the USA and worldwide. Despite the ensuing recovery, mounting financial risk and economic policy uncertainty have confounded investors, portfolio and hedge fund managers, and policy makers alike, especially in the USA and Europe.

Based on citations in Thomson Reuters ISI, Google Scholar, Microsoft Academic Search, RePEc (Research Papers in Economics and Finance), and paper downloads and abstract views in SSRN (Social Science Research Network), research papers in financial risk management and economic policy uncertainty are among the most widely cited, downloaded and viewed articles in finance and financial economics.

Financial risk management is difficult at the best of times, but especially so in the presence of economic policy uncertainty. The special issue will present an extensive range of papers by leading scholars in the field on "Advances in Financial Risk Management and Economic Policy Uncertainty”. The purpose of the special issue is to highlight a number of areas of research in which novel econometric, financial econometric and empirical finance methods have contributed significantly to the analysis of financial risk management when there is economic policy uncertainty, especifically the power of print: uncertainty shocks, markets, and the economy (Alexopoulos and Cohen, 2014), determinants of the banking spread in the Brazilian economy: the role of micro and macroeconomic factors (Almeida and Divino, 2014), 
forecasting value-at-risk using block structure multivariate stochastic volatility models (Asai, Caporin and McAleer, 2014), the time-varying causality between spot and futures crude oil prices: a regime switching approach (Balcilar, Gungor and Hammoudeh, 2014), a regimedependent assessment of the information transmission dynamics between oil prices, precious metal prices and exchange rates (Balcilar, Hammoudeh and Fru Asaba, 2014), a practical approach to constructing price-based funding liquidity factors (Bouwman, Buis, PieterseBloem and Tham, 2014), realized range volatility forecasting: dynamic features and predictive variables (Caporin and Velo, 2014), modelling a latent daily tourism financial conditions index (Chang, 2014), bank ownership, financial segments and the measurement of systemic risk: an application of CoVaR (Drakos and Kouretas, 2014), model-free volatility indexes in the financial literature: a review (Gonzalez-Perez, 2014), robust hedging performance and volatility risk in option markets: application to Standard and Poor's 500 and Taiwan index options (Han, Chang, Kuo and Yu, 2014), price cointegration between sovereign CDS and currency option markets in the financial crises of 2007-2013 (Hui and Fong, 2014), whether zombie lending should always be prevented (Jaskowski, 2014), preferences of risk-averse and risk-seeking investors for oil spot and futures before, during and after the global financial crisis (Lean, McAleer and Wong, 2014), managing financial risk in Chinese stock markets: option pricing and modeling under a multivariate threshold autoregression ( $\mathrm{Li}, \mathrm{Ng}$ and Chan, 2014), managing systemic risk in The Netherlands (Liao, Sojli and Tham, 2014), mean-variance portfolio methods for energy policy risk management (Marrero, Puch and Ramos-Real, 2014), on robust properties of the SIML estimation of volatility under micro-market noise and random sampling (Misaki and Kunitomo, 2014), ALRIGHT: Asymmetric LaRge-Scale (I)GARCH with Hetero-Tails (Paolella and Polak, 2014), the economic fundamentals and economic policy uncertainty of Mainland China and their impacts on Taiwan and Hong Kong (Sin, 2014), prediction and simulation using simple models characterized by nonstationarity and seasonality 
(Swanson and Urbach, 2014), and volatility forecast of stock indexes by model averaging using high frequency data (Wang and Nishiyama, 2014).

The interesting, timely and novel contributions to this special issue should highlight and encourage innovative research in a variety of challenging areas associated with the topical and rapidly expanding areas of financial risk management and economic policy uncertainty.

The plan of the remainder of the paper is as follows. An overview of the 22 papers is presented in Section 2, and some final remarks are given in Section 3.

\section{Overview}

The first paper is "The power of print: Uncertainty shocks, markets, and the economy" by Michelle Alexopoulos (Department of Economics, University of Toronto, Canada) and Jon Cohen (Department of Economics, University of Toronto, Canada). There has been in recent years a renewed interest in, and a growing recognition of, the role played by uncertainty shocks in driving fluctuations in the economy and in asset markets. The authors create new text-based indicators of both general economic and policy-specific uncertainty from New York Times and use them to chart changes in the level of uncertainty in the USA for the period 1985-2007, to determine the role of policy in these swings, and to assess their impact on the economy, equity markets, and business cycles. Overall, the results indicate that uncertainty shocks, both general and policy related, depress the level of economic activity, significantly increase stock market volatility, and decrease market returns.

In the second paper, "Determinants of the banking spread in the Brazilian economy: The role of micro and macroeconomic factors”, Fernanda Dantas Almeida (Department of Economics, 
Catholic University of Brasilia, Brazil) and Jose Angelo Divino (Department of Economics, Catholic University of Brasilia, Brazil) use an empirical model to identify the major determinants of the ex-post banking spread in the Brazilian economy, considering the influence of the macroeconomic environment, specific characteristics of the financial institutions, and elements of the banking sector. The sample consists of a balanced panel, composed of 64 banks in the period between the first quarter of 2001 and the second quarter of 2012. The empirical results of the static model suggest that administrative expenses, revenue from services and the coverage index are important determinants of the ex-post spread. The macroeconomic environment shows positive effects arising from real GDP, while the Herfindahl-Hirschman index indicates that spreads are higher for a more concentrated banking system. The dynamic model reveals a moderate persistence for the ex-post banking spread and a rise in relevance for the banks' market share. The overall pure spread indicates that banks consider the Brazilian economy to be a risky environment in which to operate.

The third paper by Manabu Asai (Faculty of Economics, Soka University, Tokyo, Japan), Massimiliano Caporin (Department of Economics and Management "Marco Fanno", University of Padova, Italy), and Michael McAleer (Department of Quantitative Finance, National Tsing Hua University, Taiwan; Econometric Institute, Erasmus School of Economics, Erasmus University Rotterdam; Tinbergen Institute, The Netherlands) is on "Forecasting value-at-risk using block structure multivariate stochastic volatility models”. Most multivariate variance or volatility models suffer from a common problem, the "curse of dimensionality". For this reason, most are fitted under strong parametric restrictions that reduce the interpretation and flexibility of the models. Recently, the literature has focused on multivariate models with milder restrictions, whose purpose is to combine the need for interpretability and efficiency faced by model users with the computational problems that may emerge when the number of assets can be very large. A contribution to this strand of the literature including a 
block-type parameterization for multivariate stochastic volatility models is provided. The empirical analysis on stock returns on the US market shows that $1 \%$ and $5 \%$ Value-at-Risk thresholds based on one-step-ahead forecasts of covariances by the new specification are satisfactory for the period including the Global Financial Crisis.

"The time-varying causality between spot and futures crude oil prices: A regime switching approach”, the fourth paper, is by Mehmet Balcilar (Department of Economics, Eastern Mediterranean University, Turkey), Hasan Gungor (Department of Economics, Eastern Mediterranean University, Turkey), and Shawkat Hammoudeh (Lebow College of Business, Drexel University, USA). A puzzling result in the literature on the linkages between crude oil spot and futures prices is the sensitivity of causality tests to the sample period, which has been handled in the literature by sample splitting. In order to overcome this difficulty, the authors propose a model that allows for time-varying Granger causality. The model is used to investigate the time-varying causal linkages between the daily crude oil spot and futures prices for maturities of one, two, three and four months of the West Texas Intermediate (WTI) crude oil benchmark for the period January 2, 1986 to July 31, 2013. The empirical results indicate that the causal links between these oil prices are strongly time varying. Both variables have predictive power for each other during various sub-periods, but not for all periods. Furthermore, these periods coincide with major changes in the oil and stock markets and geopolitics, implying that the empirical findings are not statistical artifacts, but reflect real economic, financial and geopolitical regime changes. The full sample's conditional Granger causality tests based on the Markov switching vector-error correction (MS-VEC) model reject both the causal impact of the lagged futures prices on the spot prices, and the causal impact from the lagged spot prices to the futures prices. Therefore, the results show that the lead-lag relationship between the spot and futures oil markets exists only temporarily. The results encompass existing empirical results and offer new insights into the nature of the lead-lag 
relationships between the spot and futures oil markets by accounting for non-linearity and time variation.

The fifth paper by Mehmet Balcilar (Department of Economics, Eastern Mediterranean University, Turkey), Shawkat Hammoudeh (Lebow College of Business, Drexel University, USA), and Nwin-Anefo Fru Asaba (Department of Economics, Eastern Mediterranean University, Turkey) is entitled “A regime-dependent assessment of the information transmission dynamics between oil prices, precious metal prices and exchange rates”. The authors use the Bayesian Markov-Switching Vector Error Correction (MSVEC) model and the regime-dependent impulse response functions (RDIRF) to examine the transmission dynamics of oil spot prices, precious metals (gold, silver, platinum, and palladium) spot prices and the US dollar/euro exchange rate. Using daily data from 1987 to 2012, two regimes (namely, low and high volatility regimes) seem to be suitable empirically. The authors find that gold prices are the most informative in the high volatility regime, while gold, palladium, and platinum are the most informative in the low volatility regime. While the platinum and palladium prices impact each other, the impacts in the high volatility regime are asymmetric. In addition to its low correlation in the group, the negative impact of palladium on the exchange rate and gold makes it a reliable hedge asset for investors. Gold is the least volatile variable, thereby affirming its use as a "safe haven" asset, while silver and oil are the most volatile in the group. Understanding the dynamics of these commodity prices should help investors decide how to invest during periods of low and highly volatility regimes.

“A practical approach to constructing price-based funding liquidity factors” is the sixth paper, by Kees Bouwman (Cardano Risk Management, The Netherlands), Boyd Buis (Econometric Institute, Erasmus University Rotterdam, The Netherlands, KAS Bank), Mary PieterseBloem (Econometric Institute, Erasmus University Rotterdam, The Netherlands, APG Asset 
Management), and Wing Wah Tham (Econometric Institute, Erasmus University Rotterdam, and Tinbergen Institute, The Netherlands). The paper proposes a computationally convenient and parsimonious approach for creating a funding liquidity factor, building on work that relates the funding constraints of financial institutions to their ability to exploit arbitrage opportunities. By studying mispricing among bonds of similar characteristics but of different ages, the Fontaine-Garcia approach uses an arbitrage-free Nelson-Siegel framework to construct a pricebased liquidity factor. However, this requires the use of a non-linear Kalman filter, which is computationally intensive in practice. The novelty of the paper is to suggest an easier method for constructing an alternative liquidity factor that retains much of the same properties. The authors construct an alternative liquidity factor estimate by relaxing the arbitrage-free assumption in the specification of the term structure model, and base it on a simple and flexible term structure specification. They demonstrate that this parsimonious liquidity factor fits the data well. The constructed factor is highly correlated with the Fontaine-Garcia liquidity factor and other funding liquidity measures, such as the liquidity factor, the TED-spread and the CPspread.

Massimiliano Caporin (Department of Economics and Management "Marco Fanno", University of Padova, Italy) and Gabriel Velo (Department of Economics and Management “Marco Fanno”, University of Padova, Italy) present the seventh paper, namely "Realized range volatility forecasting: Dynamic features and predictive variables”. The authors estimate, model and forecast Realized Range Volatility, a realized measure and estimator of the quadratic variation of financial prices. The realized range was developed very early in the literature and is based on the high-low range observed at high frequency during the day. The paper considers the impact of the microstructure noise in high frequency data and corrects the estimates based on a standard procedure. The authors model the Realized Range and account for the well-known stylized effects that are present in financial data, and investigate the role 
that macroeconomic and financial variables play when forecasting daily stock volatility. They consider a Heterogeneous Autoregressive (HAR) model with asymmetric effects with respect to the volatility and returns, and GARCH and GJR specifications for the conditional variance equation. Moreover, the authors consider a non-Gaussian distribution for the innovations. Finally, the paper extends the model by including macroeconomic and financial variables that capture the current and future states of the economy. It is found that these variables are significantly correlated with the first common component of the volatility series and have high in-sample explanatory power. The analysis of the forecast performance of 16 NYSE stocks suggests that the introduction of asymmetric effects with respect to the returns and volatility in the HAR model result in significant improvements in the point forecasting accuracy, as well as the variables related to the U.S. stock market performance and proxies for the credit risk.

The eighth paper, "Modelling a latent daily tourism financial conditions index", is by Chia-Lin Chang (Department of Applied Economics and Department of Finance, National Chung Hsing University, Taiwan). The paper uses daily data on financial stock index returns, tourism stock sub-index returns, exchange rate returns and interest rate differences from June 1, 2001 to February 28, 2014 for Taiwan to construct a novel latent daily tourism financial indicator, namely the Tourism Financial Conditions Index (TFCI). The TFCI is an adaptation and extension of the widely-used Monetary Conditions Index (MCI) and Financial Conditions Index (FCI) to tourism stock data. However, the method of calculation of the daily TFCI is different from existing methods of constructing the MCI and FCI in that the weights are estimated empirically. Alternative versions of the TFCI are constructed, depending on the appropriate model and method of estimation, namely Ordinary Least Squares (OLS) or Quasi-Maximum Likelihood Estimation (QMLE) of alternative conditional volatility models. Three univariate conditional volatility models are considered, namely GARCH, GJR 
and EGARCH, in an attempt to capture the inherent volatility in the daily tourism stock index returns. The empirical findings show that TFCI is estimated quite accurately using the estimated conditional mean of the tourism stock index returns, especially when conditional volatility is incorporated in the overall specification. The new daily TFCI is straightforward to use and interpret, and provides interesting insights in predicting the current economic and financial environment for tourism stock index returns, especially as it is based on straightforward calculations and interpretations of publicly available information.

"Bank ownership, financial segments and the measurement of systemic risk: An application of CoVaR”, is the ninth paper, by Anastassios A. Drakos (Department of Business Administration, Athens University of Economics and Business, Greece) and Georgios P. Kouretas (Department of Business Administration, Athens University of Economics and Business, Greece). The recent financial crisis has shown that the regulatory framework that has been formulated and implemented over the last twenty years under the Basel I and II agreements has relied excessively on the monitoring of individual financial institutions. It failed to capture the contribution of systemic risk, which is considered to be the risk that is the outcome of collective behaviour of financial institutions that have significant effects on the real economy. This paper investigates whether the increased presence of foreign banks which are listed on a national stock market has contributed to the increase in the systemic risk, in particular, after the global financial crisis of 2007-2009. The authors examine the extent to which the distress of foreign banks contributes to systemic risk for the USA. In addition, using relevant data for the UK, they investigate the extent to which distress within different subsegments of the financial system, namely the banking, insurance and other financial services industries, contribute to systemic risk. The analysis is conducted using the recently developed CoVaR measure of systemic risk using daily data for the period 2 January 2000 to 31 December 2012. Furthermore, the authors complement their analysis with the application of 
two tests, the significance and dominance tests, to provide a formal comparison of the relative contribution of either the domestic or foreign banks and/or each individual financial sector. The main results provide evidence that in the USA, the non-US banks contribute to the systemic risk, although most of the contribution comes from the US banks. In the case of the UK, the authors find that the banking industry contributes relatively more to systemic risk in periods of distress than the insurance industry or the other financial services industry. Furthermore, when they examine the estimated change in CoVaR measures, it is observed that the contribution to systemic risk has increased since 2008 for all sectors.

Maria Teresa Gonzalez-Perez (Colegio Universitario de Estudios Financieros (CUNEF), Madrid, Spain) presents the tenth paper on "Model-free volatility indexes in the financial literature: A review”. The paper describes the primary uses of the VIX index in the financial literature, offering for the first time a joint view of the successes and failures of VIX in key financial areas. VIX is a model-free volatility index that measures the investor "fear" due to its significant and negative relationship with the S\&P 500 returns dynamics, which justifies its use as a proxy for market risk and volatility. Of all the uses made of VIX, this article focuses on the most frequent, namely as: (1) a financial product to hedge a portfolio against volatility risk; (2) a market risk measure used to analyze risk flows from financial markets, and relate private and public risks; and (3) a volatility measure to use in the estimation of the spot volatility dynamics, the volatility risk premium and volatility jumps. The current literature continues to use VIX in a similar way. The paper offers an introductionfor researchers who consider VIX as a proxy for volatility and/or risk.

In the eleventh paper, "Robust hedging performance and volatility risk in option markets: Application to Standard and Poor's 500 and Taiwan index options”, Chuan-Hsiang 
Han (Department of Quantitative Finance, National Tsing Hua University, Taiwan), ChienHung Chang (Department of Financial and Computational Mathematics, Providence University, Taiwan), Chii-Shyan Kuo (Department of Accountancy, National Cheng Kung University, Taiwan), and Shih-Ti Yu (Department of Quantitative Finance, National Tsing Hua University, Taiwan) investigate the daily robust hedging performance with trading costs for both the S\&P 500 Index option (SPX) and Taiwan Index option (TXO) markets. A theoretical analysis is presented to cope with the price limit constraint in TXO. Robust hedging refers to minimal model dependence on the risky asset price. Two hedging categories, including “model-free” and "volatility-model-free," are investigated, and nonparametric methods for volatility estimation are considered in the empirical analysis. In particular, the instantaneous volatility is estimated by a novel nonlinear correction scheme of the Fourier transform method, which is justified in a simulation study for a local volatility model. An asymmetric phenomenon of hedging performance is found. Hedging portfolios constructed from the "volatility-model-free" category are found to induce much higher Sharpe ratios than those from the "model-free" category on SPX, while they are found to perform comparably on TXO. Owing to price limit regulations in Taiwan, the paper also develops a time-scale change method to explain this phenomenon. The asymptotic moment estimates of differences in some hedging portfolios are found to be consistent with the empirical findings.

The twelfth paper on "Price cointegration between sovereign CDS and currency option markets in the financial crises of 2007-2013”, is by Cho-Hoi Hui (Research Department, Hong Kong Monetary Authority, Hong Kong, China) and Tom Pak-Wing Fong (Research Department, Hong Kong Monetary Authority, Hong Kong, China). The sovereign credit default swap (CDS) spreads and exchange rates of developed economies, including the USA, Japan, Switzerland and the Eurozone, with the first three countries' currencies conventionally 
considered as safe havens, have varied over a wide range during the financial crises since late2007. This raises the question as to any interconnectivity between the anticipated sovereign credit risks of these economies and the market expectations of their exchange rates. Using a bivariate vector error-correction model with random coefficients, the authors find evidence of cointegration and time-varying conditional correlation between the prices in the sovereign CDS and currency option markets. The empirical results show that the relative sovereign credit risks of these developed economies impacts the market expectations of their exchange rates in the long run. In the short run, the impact changes drastically in times of crisis, resulting in drastic and persistent price deviations from their long-run equilibrium amid monetary measures by central banks and market turbulence.

Marcin Jaskowski (Econometric Institute, Erasmus School of Economics, Erasmus University Rotterdam, The Netherlands) asks and answers the question "Should zombie lending always be prevented?” in the thirteenth paper. It has been argued that zombie lending might have been one of the main culprits behind the sluggish Japanese recovery in the so-called "lost decade". Among others, zombie lending may lead to misallocation of capital, reduction of profits for healthy firms, and lower employment. The only remaining question is: Why do banks engage in zombie lending practices? Is it due to wrong incentives for bank managers, or perhaps misguided government policies? Using a simple model, the paper exposes a strong link between collateral value and the strategic importance of zombie lending. The author shows that zombie lending may be an optimal strategy for a bank in some cases as it leads to greater lending ex-ante and prevents further losses from fire sales. Consequently, it can be argued that zombie lending is a side effect of market incompleteness and is ex ante welfare improving, so that it may not be possible or even desirable to prevent its occurrence. Another policy implication is that capital injection into banks would not solve the problem. However, direct 
purchases of the collateral on the market would certainly alleviate the problem of zombie lending.

In the fourteenth paper, "Preferences of risk-averse and risk-seeking investors for oil spot and futures before, during and after the global financial crisis”, Hooi Hooi Lean (Economics Program, School of Social Sciences, University Sains Malaysia), Michael McAleer (Department of Quantitative Finance, National Tsing Hua University, Taiwan; Econometric Institute, Erasmus School of Economics, Erasmus University Rotterdam; Tinbergen Institute, The Netherlands), and Wing-Keung Wong (Department of Economics, Hong Kong Baptist University, Hong Kong, China) examine risk-averse and risk-seeking investor preferences for oil spot and futures prices before, during and after the global financial crisis by using the mean-variance (MV) criterion, the CAPM statistics, and stochastic dominance (SD) approach. The MV criterion shows that risk averters are indifferent between oil spot and futures prices, but risk seekers prefer to invest in oil futures rather than spot prices. The information drawn from the CAPM statistics does not lead to any preference between oil spot and futures prices. The SD tests show that risk-averse investors prefer the spot index, whereas risk seekers are attracted to the futures index to maximize expected utility, though not expected wealth for the entire period, as well as for the sub-period before the 2008 Global Financial Crisis (GFC) and the sub-periods during and after the GFC. In order to compare the performance of spot prices in the pre-GFC and GFC sub-periods, it is found that the 2008 GFC has no impact on the means and variances, or the CAPM statistics. Moreover, the SD analysis reveals that spot prices from the pre-GFC and GFC sub-periods do not dominate each other, both risk averters and risk seekers are indifferent between the spot prices from the pre-GFC and GFC sub-periods, there is no arbitrage opportunity for spot prices before and after the GFC, and the spot market is efficient with respect to the GFC crisis. A similar conclusion is drawn regarding the impact of the GFC on the oil futures prices. The empirical findings in the 
paper provide useful information for academics, practitioners, and policy makers in their decisions regarding oil spot and futures markets, as well as towards the likely impacts of any significant financial crisis in the future.

Johnny S.H. Li (Department of Statistics and Actuarial Science, University of Waterloo, Canada), Andrew. C.Y. Ng (Department of Finance, Chinese University of Hong Kong, Hong Kong, China), and Wai-Sum Chan (Department of Finance, Chinese University of Hong Kong, Hong Kong, China) examine "Managing financial risk in Chinese stock markets: Option pricing and modeling under a multivariate threshold autoregression” in the fifteenth paper. The Shanghai Stock Exchange and the Shenzhen Stock Exchange in Mainland China have grown remarkably since their inception 20 years ago. Many investors in these two markets are asset management firms or pension funds, some of which may offer guaranteed returns to their clients. To these investors, modeling and managing the risk associated with their equity investments are very important. The authors use a multivariate Threshold AutoRegressive (TAR) process to model the non-linear relationship between these two markets. The model may help fund managers better plan or execute their risk management decisions as it captures the difference in behaviour of investment returns when one market significantly outor under-performs the other. The authors also develop a risk-neutral version of the multivariate TAR model. This contribution permits price exotic options to be written on multiple stock indexes, and consequently helps fund managers calculate the cost of an option-based risk management strategy for funds involving the two Chinese markets.

"Managing systemic risk in The Netherlands" is the sixteenth paper, by Shuyu Liao (Erasmus University Rotterdam, The Netherlands), Elvira Sojli (Rotterdam School of Management, Erasmus University Rotterdam, The Netherlands), and Wing Wah Tham (Econometric Institute, Erasmus University Rotterdam, and Tinbergen Institute, The Netherlands). The paper 
investigates the effects on systemic risk of macroprudential capital requirements, which require banks to hold capital that is proportional to the bank's contribution to systemic risk. The authors use a panel of correlated Merton balance sheet models, combined with a network clearing algorithm, to measure systemic risk and how it changes with bank capital. The model explicitly incorporates the possibility of default through common exposures to macroeconomic factors and interbank exposures. They use five risk allocation mechanisms to allocate systemic risk to individual banks. Using a sample of Dutch banks, the authors find that the macroprudential capital requirements deviate from the current observed capital levels by as much as $40 \%$, and are positively related to bank size and interbank exposure. Furthermore, it is found that macroprudential capital requirements can reduce individual and multiple banks default probabilities by up to $26 \%$, and are robust to model risk. The results suggest that financial stability can be substantially improved by implementing macroprudential regulations for the banking system.

Gustavo A. Marrero (Department of Economics, Universidad de La Laguna, Tenerife, Spain), Luis A. Puch (Department of Economics, Complutense University of Madrid, Spain), Francisco J. Ramos-Real (Department of Economics, Universidad de La Laguna, Tenerife, Spain) consider "Mean-variance portfolio methods for energy policy risk management” in the seventeenth paper. The risks associated with the current and prospective costs of different energy technologies are crucial in assessing the efficiency of the energy mix. However, energy policy typically relies on the evolution of average costs, neglecting the covariances in the costs of the different energy technologies in the mix. In the paper, MeanVariance Portfolio Theory is implemented to evaluate jointly the average costs and the associated volatility of alternative energy combinations. Based on a Capital Asset Pricing Model with time-varying betas, the systematic and non-systematic risks associated with energy technologies are computed. The authors show that both electricity generation and fuel use 
imply risks that are idiosyncratic, with relevant implications for energy and environmental policy.

In the eighteenth paper, Hiroumi Misaki (Research Center for Advanced Science and Technology, University of Tokyo, Japan) and Naoto Kunitomo (Graduate School of Economics, University of Tokyo, Japan) investigate issues associated with "On robust properties of the SIML estimation of volatility under micro-market noise and random sampling”. For estimating the integrated volatility and covariance by using high frequency data, the Separating Information Maximum Likelihood (SIML) method in the presence of micro-market noise has been proposed in the literature. The SIML estimator has reasonable finite sample properties and asymptotic properties when the sample size is large, under general conditions with non-Gaussian processes or volatility models. The paper shows that the SIML estimator is asymptotically robust in the sense that it is consistent and has stable convergence (that is, asymptotic normality in the deterministic case), as well as reasonable finite sample properties, when there is micro-market noise and the observed high frequency data are sampled randomly with the underlying (continuous time) stochastic process. The authors also discuss some implications of the results on public policy and risk management in financial markets.

“ALRIGHT: Asymmetric LaRge-Scale (I)GARCH with Hetero-Tails” is the nineteenth paper, by Marc S. Paolella (Department of Banking and Finance, University of Zurich, Switzerland) and Pawel Polak (Department of Banking and Finance, University of Zurich, Switzerland). It is well known in empirical finance that virtually all asset returns, whether monthly, daily, or intraday, are heavy-tailed and, particularly for stock returns, are mildly but often significantly negatively skewed. However, the tail indices, or maximally existing moments of the returns, can differ markedly across assets. In order to accommodate these stylized facts when modeling the joint distribution of asset returns, an asymmetric extension of the meta-elliptical $t$ 
distribution is proposed. While the likelihood is tractable, for high dimensions it will be impractical to use for estimation. In order to address this issue, a fast, two-step estimation procedure is developed, based on a saddlepoint approximation to the noncentral Student $\mathrm{t}$ distribution. The model is extended to support a CCC-(I)GARCH structure, and is demonstrated by modeling and forecasting the return series comprising the DJIA. The techniques of shrinkage, time-varying tail dependence, and weighted likelihood are used to enhance the forecasting performance of the model with no added computational burden.

In the twentieth paper, entitled "The economic fundamentals and economic policy uncertainty of Mainland China and their impacts on Taiwan and Hong Kong”, Chor-yiu (CY) Sin (Department of Economics, National Tsing Hua University, Taiwan) Observes that the opening-up of Mainland China has significantly increased its economic relationship with Taiwan and Hong Kong. Trade among Taiwan, Hong Kong and Mainland China has registered record highs in recent years, and capital flow has grown exponentially. The paper applies structural vector autoregressive (SVAR) models to the Taiwan and Hong Kong economies to investigate the impacts of the Chinese economy over the past decade. Identification of the structural shocks is based on the fact that Mainland China has a causal effect on Taiwan and Hong Kong, but not the reverse. The identification scheme generalizes the Blanchard and Quah procedure, and considers both short-run and long-run restrictions. Based on a New Keynesian model, a simple model with four domestic variables, namely output, interest rate, price level and real exchange rate, as well as two foreign variables, namely Mainland China's output and the China monthly index of economic policy uncertainty, is constructed. By considering the short-run and long-run impacts, the paper addresses whether domestic output or some other domestic variables are affected by the uncertain economic conditions in the short or long run. 
The penultimate paper by Norman R. Swanson (Department of Economics, Rutgers University, USA), Richard Urbach (Conning Germany GmbH), is entitled "Prediction and simulation using simple models characterized by nonstationarity and seasonality”. The paper provides new evidence on the empirical usefulness of various simple seasonal models, and underscores the importance of carefully designing criteria by which to judge alternative models. In particular, the authors underscore the importance of both choice of forecast or simulation horizon and choice between minimizing point or distribution-based loss measures. The empirical analysis centers around the implementation of a series of simulation and prediction experiments, as well as a discussion of the stochastic properties of seasonal unit root models. The prediction experiments are based on an analysis of a group of 14 variables that have been chosen to mimic closely the set of indicators used by the Federal Reserve to help in setting U.S. monetary policy. The simulation experiments are based on a comparison of simulated and historical distributions of the variables. A key impetus for the paper stems from the fact that various financial service companies routinely create “economic scenarios”, whereby seasonal and nonstationary financial and economic variables are simulated (and predicted) using relatively simple time series models. These “economic scenarios” are subsequently used in risk management and asset allocation, as is often mandated by various world financial regulatory authorities. The empirical findings suggest that a simple version of the seasonal unit root (SUROOT) model performs very well for predicting 8 of 14 variables, when the forecast horizon is 1-step ahead. However, for horizons of greater than one-step ahead, the SUROOT model performs poorly when used for prediction, suggesting that parameter estimation error is crucial to understanding the empirical performance of such models. This "parameter estimation error” result is confirmed via a series of Monte Carlo experiments. Simulation experiments yield similar conclusions, although SUROOT models in this case are useful for constructing “forward" conditional distributions at 1- and 3-step ahead horizons. Interestingly, simple 
periodic autoregressions do not have this property, and are found to perform very well in both prediction and simulation experiments, at all horizons up to 60 months ahead.

The final paper, entitled "Volatility forecast of stock indexes by model averaging using high frequency data”, is by Chengyang Wang (Graduate School of Economics, Kyoto University, Japan) and Yoshihiko Nishiyama (Institute of Economic Research, Kyoto University, Japan). Models from the GARCH class perform well in the analysis of volatility forecasts. The authors use the realized GARCH (RGARCH) model, high frequency based volatility (HEAVY) model, and multiplicative error model (MEM) to evaluate the performance of the one-day ahead volatility forecasts of Chinese and Japanese stock indices. They propose to combine the models by the model averaging technique to explore the possibility of obtaining better predictions. The CSI 300 and Nikkei 225 indexes are used in the empirical analysis. The authors use rolling estimation and predict the daily volatilities. They evaluate the forecast performance by the superior predictive ability (SPA) test. As a result, they find that combination methods significantly improve the forecast performance compared with the best single model predictions.

\section{Final remarks}

The collection of interesting, timely and novel papers in this special issue by some of the leading experts in the field of “Advances in Financial Risk Management and Economic Policy Uncertainty" should both highlight and encourage innovative research in a variety of challenging areas associated with the topical and rapidly expanding areas of financial risk management and economic policy uncertainty. 
It is our pleasure to acknowledge all the contributors for preparing their invaluable, interesting and innovative papers in a timely manner, and for their willingness to participate in the rigorous editorial review process. 


\section{References}

Alexopoulos, M. and J. Cohen (2014), The power of print: Uncertainty shocks, markets, and the economy, to appear in International Review of Economics and Finance.

Almeida, F.D. and J.A. Divino (2014), Determinants of the banking spread in the Brazilian economy: The role of micro and macroeconomic factors, to appear in International Review of Economics and Finance.

Asai, M., M. Caporin and M. McAleer (2014), Forecasting value-at-risk using block structure multivariate stochastic volatility models, to appear in International Review of Economics and Finance.

Balcilar, M., H. Gungor and S. Hammoudeh (2014), The time-varying causality between spot and futures crude oil prices: A regime switching approach, to appear in International Review of Economics and Finance.

Balcilar, M., S. Hammoudeh and N.-A. Fru Asaba (2014), A regime-dependent assessment of the information transmission dynamics between oil prices, precious metal prices and exchange rates, to appear in International Review of Economics and Finance.

Bouwman, K., B. Buis, M. Pieterse-Bloem and W.W. Tham (2014), A practical approach to constructing price-based funding liquidity factors, to appear in International Review of Economics and Finance.

Caporin, M. and G. Velo (2014), Realized range volatility forecasting: Dynamic features and predictive variables, to appear in International Review of Economics and Finance.

Chang, C.-L. (2014), Modelling a latent daily tourism financial conditions index, to appear in International Review of Economics and Finance. 
Drakos, A.A. and G.P. Kouretas (2014), Bank ownership, financial segments and the measurement of systemic risk: An application of $\mathrm{CoVaR}$, to appear in International Review of Economics and Finance.

Gonzalez-Perez, M. T. (2014), Model-free volatility indexes in the financial literature: A review, to appear in International Review of Economics and Finance.

Han, C.-H., C.-H. Chang, C.-S. Kuo and S.-T. Yu (2014), Robust hedging performance and volatility risk in option markets: Application to Standard and Poor’s 500 and Taiwan index options, to appear in International Review of Economics and Finance.

Hui, C.-H. and T.P.-W. Fong (2014), Price cointegration between sovereign CDS and currency option markets in the financial crises of 2007-2013, to appear in International Review of Economics and Finance.

Jaskowski, M. (2014), Should zombie lending always be prevented?, to appear in International Review of Economics and Finance.

Lean, H.H., M. McAleer and W.-K. Wong (2014), Preferences of risk-averse and risk-seeking investors for oil spot and futures before, during and after the global financial crisis, to appear in International Review of Economics and Finance.

Li, J.S.H., A.C.Y. Ng and W.-S. Chan (2014), Managing financial risk in Chinese stock markets: Option pricing and modeling under a multivariate threshold autoregression, to appear in International Review of Economics and Finance.

Liao, S., E. Sojli and W.W. Tham (2014), Managing systemic risk in The Netherlands, to appear in International Review of Economics and Finance.

Marrero, G.A., L.A. Puch and F.J. Ramos-Real (2014), Mean-variance portfolio methods for energy policy risk management, to appear in International Review of Economics and Finance. 
Misaki, H. and N. Kunitomo (2014), On robust properties of the SIML estimation of volatility under micro-market noise and random sampling, to appear in International Review of Economics and Finance.

Paolella. M.S. and P. Polak (2014), ALRIGHT: Asymmetric LaRge-Scale (I)GARCH with Hetero-Tails, to appear in International Review of Economics and Finance.

Sin, C.-Y. (2014), The economic fundamentals and economic policy uncertainty of Mainland China and their impacts on Taiwan and Hong Kong, to appear in International Review of Economics and Finance.

Swanson, N.R. and R. Urbach (2014), Prediction and simulation using simple models characterized by nonstationarity and seasonality, to appear in International Review of Economics and Finance.

Wang, C. and Y. Nishiyama (2014), Volatility forecast of stock indexes by model averaging using high frequency data, to appear in International Review of Economics and Finance. 